\title{
Metallochlorophylls of Magnesium, Copper and Zinc: Evaluation of the Influence of the First Coordination Sphere on their Solvatochromism and Aggregation Properties
}

\author{
Leonardo M. Moreira, ${ }^{a}$ Adriana Lima, ${ }^{a}$ Rafael R. S. Soares, ${ }^{b}$ Vagner R. Batistela ${ }^{b}$ Adriana P. Gerola, ${ }^{b}$ \\ Noboru Hioka, ${ }^{b}$ Juliano A. Bonacin, ${ }^{c}$ Divinomar Severino, ${ }^{c}$ Mauricio S. Baptista, ${ }^{c}$ Antônio E. da Hora \\ Machado, ${ }^{d}$ Máira R. Rodrigues, ${ }^{a}$ Lúcia Codognoto ${ }^{a}$ and Hueder P. M. de Oliveira*,a
}

${ }^{a}$ Universidade Camilo Castelo Branco, 12247-004 São José dos Campos-SP, Brazil

${ }^{b}$ Departamento de Química, Universidade Estadual de Maringá, 87020-900 Maringá-PR, Brazil

${ }^{c}$ Departamento de Bioquímica, Instituto de Química, Universidade de São Paulo, 05508-900 São Paulo-SP, Brazil

${ }^{d}$ Instituto de Química, Universidade Federal de Uberlândia, 38408-100 Uberlândia-MG, Brazil

\begin{abstract}
No presente estudo, o papel de diferentes centros metálicos (magnésio, zinco e cobre) sobre o caráter hidrofílico de metaloclorofilas foi avaliado. O solvatocromismo, assim como o processo de agregação para esses compostos, em misturas água/etanol foram avaliados usando medidas de fluorescência e de espalhamento de luz ressonante (ELR), visando caracterizar o comportamento desses compostos. Independente da metaloclorofila estudada, a presença de ao menos $60 \%$ de água resulta em incremento considerável na emissão de fluorescência apresentada por esses compostos. Isso, provavelmente, é uma conseqüência direta de uma menor agregação, o que é confirmado pelos resultados de ELR. Adicionalmente, os resultados sugerem que as clorofilas de magnésio e de zinco devem ser promissores agentes fototerapêuticos para emprego em Terapia Fotodinâmica.

In this study the role of different metal centers (magnesium, zinc and copper) on the enhancement of the hydrophilic character of metallochlorophylls, was evaluated. The solvatochromism as well as the aggregation process for these compounds in water/ethanol mixtures at different volume ratios were evaluated using Fluorescence, and Resonant Light Scattering (RLS) measurements, aiming to characterize the behavior of these compounds. Independently on the studied metallochlorophyll, the presence of at least $60 \%$ of water results in a considerable increase in the fluorescence emission, probably a direct consequence of a lower aggregation of these compounds, which is confirmed by the results from RLS measurements. Additionally, the results suggest that magnesium and zinc chlorophyll should be promising phototherapeutic agents for Photodynamic Therapy.
\end{abstract}

Keywords: fluorescence spectroscopy, resonant light scattering, metallochlorophylls, photodynamic therapy

\section{Introduction}

Photosynthetic pigments represent a kind of "lifeblood" of all photoautotrophic organisms. There are basically three classes of natural photosynthetic pigments: chlorophylls, carothenoids and phycobilins. ${ }^{1}$ In nature, there are approximately 10 types of chlorophylls, isolated from the green part of the plants. In some organisms only chlorophyll is detected, while in other species, the main chlorophyll is accompanied by other green pigments. This principal component is the chlorophyll $\alpha$ (Figure 1),

*e-mail: huederpaulo@yahoo.com.br which is found together with the chlorophylls b, c, d and the protochlorophyll. ${ }^{2}$ It is important to register that the version of chlorophyll $\alpha$ without metallic center, where $\mathrm{Mg}^{2+}$ is substituted by two hydrogen atoms, is known as pheophytin $\alpha$, which has been previously evaluated. ${ }^{3}$ This derivative can be obtained by the acid hydrolysis of chlorophyll $\alpha$ (Figure 2). ${ }^{4}$

Chlorophyll $\alpha$ has a ubiquitous role as electron donor in photochemical reactions of oxygenic photosynthesis, in which two kinds of photosystem, namely photosystem I (PSI) and photosystem II (PSII), cooperatively drive photosynthetic electron flow from water to $\mathrm{NADP}^{+}$. The reduced cofactor, NADPH, is used for $\mathrm{CO}_{2}$ fixation. ${ }^{5}$ 


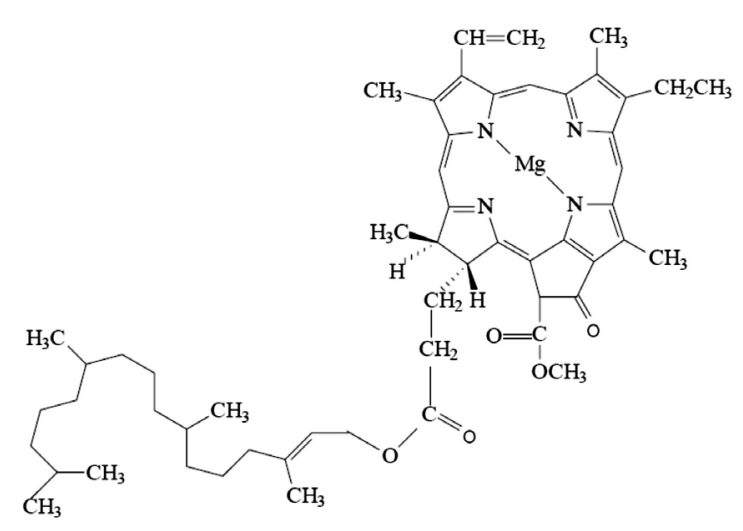

Figure 1. Structural representation of chlorophyll $\alpha$.

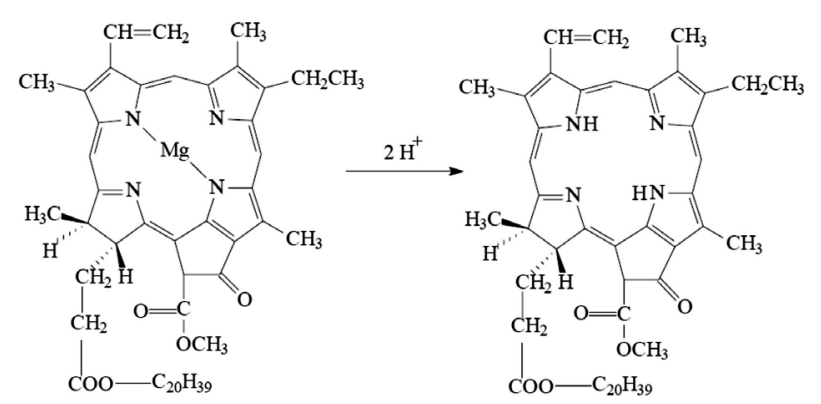

Figure 2. Schematic representation of the conversion of chlorophyll $\alpha$ to pheophytin, through acid hydrolysis.

Indeed, PS-I and PS-II have been intensively studied with different aims in the literature. ${ }^{6-8}$ It is a porphyrin derivative classified as chlorin, being metallated with $\mathrm{Mg}^{2+}$ (Figure 1). Differently from porphyrins, the molar absorptivity of the Q bands of chlorin (assigned to the $\mathrm{S}_{0} \rightarrow \mathrm{S}_{1} \pi-\pi^{*}$ electronic transition) is considerably intense, ${ }^{9,10}$ occurring into the "Phototherapeutic Window". ${ }^{10}$ Besides, this class of compounds tends to present considerably long-lived triplet excited states, being promising phototherapeutic agents in Photodynamic Therapy (PDT)..$^{10-17}$

However, one of the main limitations of chlorins and other promising phototherapeutic agents for PDT is related to the high hydrophobic character of these compounds. ${ }^{10,17}$ The high hydrophobic character tends to provoke significant aggregation of these macrocycles in water or physiological medium. Consequently, several trials have been developed in order to use metallochlorins as phototherapeutic agents for PDT, since the presence of the metallic center should decrease the hydrophobic character of the macrocycle. ${ }^{18}$ In this way, several researchers have focused their efforts on macrocyclic metallic complexes as prototypes of new photosensitizers (PS) in order to improve the efficiency of their photodynamic action in PDT.

In the present article, the solvatochromism as well as the self-assembly process for magnesium, zinc and copper chlorophylls were evaluated using fluorescence emission spectroscopy and Resonant Light Scattering (RLS).

\section{Experimental}

Eleven water/ethanol (v/v) mixtures containing magnesium, zinc or copper chlorophyll (Chl, $\left.1.44 \times 10^{-5} \mathrm{~mol} \mathrm{~L}^{-1}\right)$ were investigated. The water employed in the preparation of these mixtures presented Milli-Q degree, while ethanol was of spectroscopic degree.

Chlorophyll $\alpha$ was extracted from spinach following a procedure proposed by Dolphin. ${ }^{2}$ Pheophytin was obtained from chlorophyll $\alpha$ by a reaction with hydrochloric acid $\left(2 \mathrm{~mol} \mathrm{~L}^{-1}\right)$. Zinc and copper chlorophylls were obtained by this procedure: chlorophyll $\alpha$ was dissolved in a $2: 1(\mathrm{v} / \mathrm{v})$ chloroform/glacial acetic acid mixture. After that, an excess of zinc or copper acetate was added to this mixture, which was maintained under magnetic stirring, at room temperature, for two hours. The reaction mixture was washed with water to eliminate the excess of metallic ions. The purification of these compounds was carried out using thin layer circular chromatography-Chromatotron (Harrison Research, model 8924) with silica as stationary phase and a mixture of petroleum ether/ethanol $(95: 5, \mathrm{v} / \mathrm{v})$ as eluent. The characterization of these compounds was performed by ${ }^{1} \mathrm{H}$ NMR (Varian, Gemini $300 \mathrm{MHz}$ ).

The excitation and emission spectra were obtained using a Jobin-Yvon Spex FloroMax-2 spectrofluorimeter $($ Emission $\mathrm{slit}=$ Excitation slit $=1 \mathrm{~mm})$ and in a Ocean Optics spectrofluorimeter. The emission spectra were done using the maximum excitation intensity of both compounds. Resonant Light Scattering (RLS) spectra were obtained, in the range between 200 and $800 \mathrm{~nm}$, with $\Delta \lambda=0 \mathrm{~nm}$, in order to verify the occurrence of auto-aggregation.

All measurements were done at $298 \mathrm{~K}$. The spectra were obtained using $1 \mathrm{~cm}$ of optical pathway quartz cuvettes.

\section{Results and Discussion}

Figure 3 presents the emission spectra of magnesium, zinc and copper chlorophylls, in ethanol. The maximum emission observed for zinc chlorophyll is slightly blueshifted when compared with the one corresponding to chlorophyll $\alpha$ or copper chlorophyll. This effect is probably related to a minor contact between solvent and macrocycle for zinc chlorophyll. Being a metal cation from 2A family, $\mathrm{Mg}^{2+}$ presents a significant hygroscopic character, which must accentuate the hydrophilic character of the chlorin, favoring the accessibility of polar solvents to the macrocycle. The higher contact between ethanol and/or water and the macrocycle, in the case of magnesium 


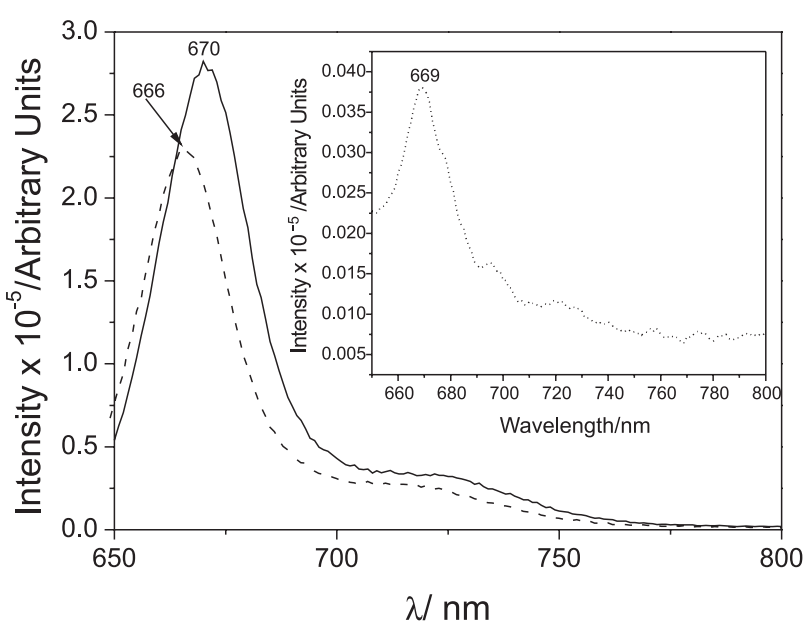

Figure 3. Emission spectra of the studied chlorophylls $\left(\mathrm{Mg}^{2+}-; \mathrm{Zn}^{2+----}\right)$ in ethanol at $298.15 \mathrm{~K}$. Inset: Emission spectrum of $\mathrm{Cu}^{2+}$ chlorophyll $(\cdots .$.$) in ethanol at 298.15 \mathrm{~K}$.

as metallic center, tends to affect more intensely the $\pi^{*}$ orbital as function of its more polarizable and accessible (external) character, reducing the energy gap between $\pi$ and $\pi^{*}$ orbitals. This results in the observed red-shift of the emission band corresponding to the $\pi-\pi^{*}$ electronic transition of chlorophyll $\alpha$ when compared with the zinc as coordination center. A similar behavior is observed for copper chlorophyll.

Figure 3 (Inset) suggests the occurrence of an intense fluorescence quenching in copper chlorophyll, certainly provoked by the paramagnetism of $\mathrm{Cu}^{2+}$. Furthermore, the specific disposition of the energy levels of the ligand field distribution in $\mathrm{Cu}^{+2}$ must favor a significant energy transfer, possibly associated to Dexter's mechanism. The synergism between these characteristics must favor the changes reported in this paper.

It is well established that metallic complexes presenting $\mathrm{a} \mathrm{d}^{9}$ electronic configuration, as the coordination compounds of $\mathrm{Cu}^{2+}$, favor a hexacoordinate configuration, with the axial coordination sites occupied by solvent molecules. Indeed, water and ethanol are Lewis bases, considered potential $\sigma$-donor ligands, capable to coordinate with $\mathrm{Cu}^{2+}$, which tend to originate a hexacoordinate metallic complex with a peculiar tetragonal distortion (Jahn-Teller Effect). However, it is known that the presence of paramagnetic metals in macrocyclic compounds results in very short triplet lifetimes, imposing a severe limitation on the usefulness of such sensitizers as photodynamic agents. ${ }^{19}$

It is evident that, for the chlorophyll derivatives studied in this work, the presence of the phytol chain (Figure 1) will introduce some hydrophobic character on these compounds. ${ }^{17,18}$ However, considering the small electronic coupling between this alkyl chain and the macrocycle, the presence of this group certainly will result in a minimal effect on the macrocycle solvation with polar solvents, as reported in this work.

The data from Table 1 and Figure 4 suggest that the fluorescence of these chlorophyll derivatives seems to have an important correlation with the level of solvation of the macrocycle with mixtures of polar solvents. However, the observed trends are minimal for copper chlorophyll. The data from Table 1 demonstrate that $\mathrm{I}_{\mathrm{F}(\max )}$ for copper chlorophyll have extremely low intensities when compared to magnesium or zinc chlorophylls. In fact, copper chlorophyll almost does not present fluorescence due to the paramagnetism of this metal ion. On the other hand, the difference in the values of $\mathrm{I}_{\mathrm{F}(\max )}$ between zinc and magnesium chlorophylls is very low.

For these three metallochlorophylls, the fluorescence intensity at the $\lambda_{\max }^{\mathrm{em}}\left(\mathrm{I}_{\mathrm{F}(\max )}\right)$ tends to increase (Table 1), mainly between 40 and $60 \%$ of water in the ethanol/water

Table 1. Maximum intensities of fluorescence emission for the studied metallochlorophylls

\begin{tabular}{lccc}
\hline \% water & \multicolumn{3}{c}{ Emission Intensity at $\lambda_{\max }^{\mathrm{em}}\left(\times 10^{-5}\right) /$ Arbitrary Units } \\
\cline { 2 - 4 } & $\mathrm{Mg}^{2+}$ & 2.29 & $\mathrm{Zn}^{2+}$ \\
\hline 0 & 2.79 & 3.55 & 0.04 \\
10 & 6.50 & 4.37 & 0.03 \\
20 & 7.39 & 4.81 & 0.02 \\
30 & 12.36 & 6.87 & 0.03 \\
40 & 16.35 & 83.54 & 0.02 \\
50 & 39.70 & 850.44 & 0.02 \\
60 & 177.61 & 1020.81 & 0.08 \\
70 & - & - & 0.16 \\
80 & 182.88 & 848.17 & 0.15 \\
90 & 189.55 & & - \\
\hline
\end{tabular}

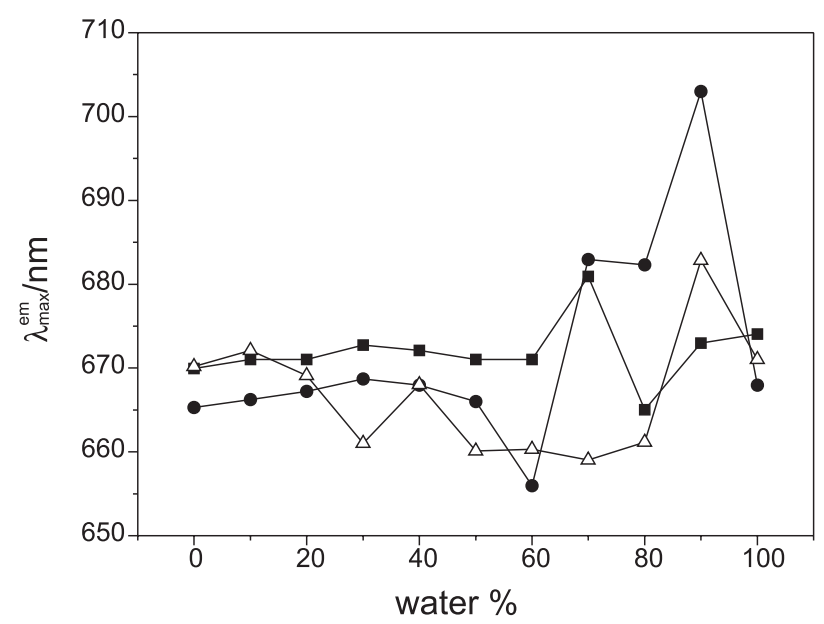

Figure 4. Variation of the emission maximum intensity for the studied chlorophylls $\left(\boldsymbol{\square}, \mathrm{Mg}^{2+} ; \triangle, \mathrm{Zn}^{2+} ; \bullet, \mathrm{Cu}^{2+}\right)$ as function of solvent composition at $298.15 \mathrm{~K}$. 
mixture, mainly for zinc and magnesium chlorophylls. For copper chlorophyll, the increase of $\mathrm{I}_{\mathrm{F}(\max )}$ is more discrete (Figure 3, Inset and Table 1), occurring for water proportions between 50 and $65 \%$.

Figure 4 presents the correlation between the emission wavelength at the emission maximum $\left(\lambda_{\max }^{\mathrm{em}}\right)$ and the $\%$ of water in the solvent mixture. For magnesium chlorophyll, the $\lambda_{\max }^{\mathrm{em}}$ tends to suffer a red shift as the water content increases in the mixture, until about $70 \%$ of water, evidently a consequence of an efficient solvation of the macrocycle, influenced by the metal centre. The improvement in the solvation implies in the diminish of the energy gap between the $\pi$ and $\pi^{*}$ states. A similar behavior is observed for the absorption spectra of these compounds (not shown). For copper chlorophyll an opposite effect is initially observed, probably due to the differentiated characteristics of this complex, for which the excited state deactivation is improved by the paramagnetism of the metal centre. ${ }^{19}$ However, between 80 and $90 \%$ of water, although not comparable with the observed for magnesium or zinc chlorophylls, a small trend of red shift of the emission band is also observed.

For zinc chlorophyll, the solvation also exerts a significant role on its fluorescence (Table 1). A significant red shift is observed for the emission band of this compound in the range between 60 and 90\% of water (Figure 4). However, below this range, between 0 and $50 \%$ of water, a minimal spectral shift is observed.

For magnesium chlorophyll, in the range between 40 and $60 \%$ of water (Figure 5), an abrupt transition in the emission intensities is observed. Above $60 \%$ of water the absorption (not shown) and emission intensities reach an optimal condition, indicating that the range between 60 and $100 \%$ of water, for the water/ethanol mixtures, constitutes

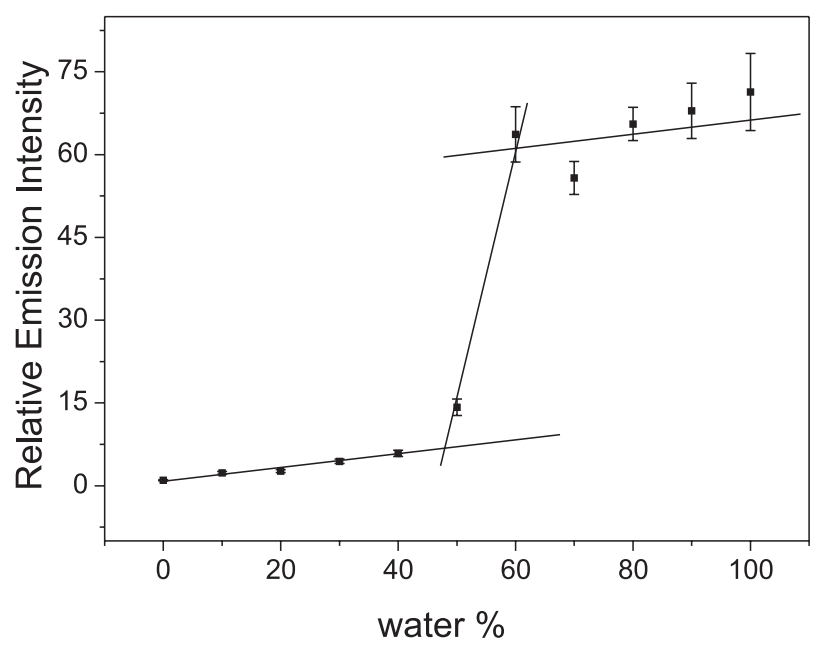

Figure 5. Variation of the emission relative intensity for magnesium chlorophyll as function of the solvent composition at $298.15 \mathrm{~K}$. a potential ratio to trials using this chlorophyll derivative as promising PS for PDT.

Figure 6 shows, for zinc chlorophyll, that a similar abrupt transition in the emission intensity is observed the range between 50 and $70 \%$ of water. Above $70 \%$ of water, the absorption (not shown) and emission intensities reach an optimal for the use of this chlorophyll derivative in assays aiming to establish this compound as PS for PDT.

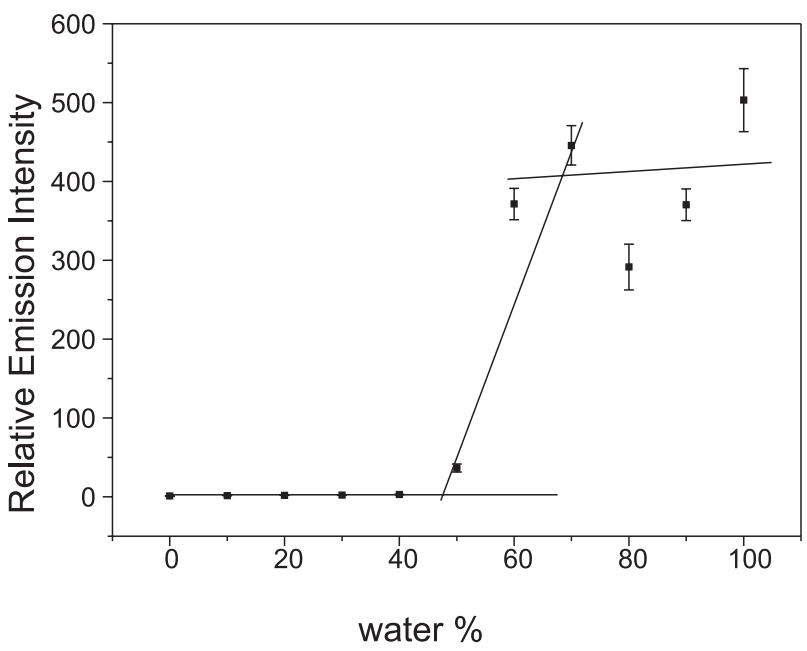

Figure 6. Variation of the relative emission intensity for zinc chlorophyll as function of the solvent composition, at $298.15 \mathrm{~K}$.

In fact, the intense absorption and emission intensities presented by these two chlorophyll derivatives are relevant parameters that suggest that, under the presented solvation conditions, these macrocyclic compounds can be capable to sensitize Reactive Oxygen Species (ROS), such as singlet oxygen, an important pre-requisite to be considered in a selection process of potential photosensitizers for PDT.

Finally, Figure 7 presents the changes observed in $\mathrm{I}_{\mathrm{F}(\max )}$ for copper chlorophyll. For this compound the observed changes are much less drastic, with a discrete jump occurring approximately between $50 \%$ and $70 \%$ of water. Due to the known characteristics of compounds possessing paramagnetic metal ions coordinated to the macrocycle,$^{19}$ this chlorophyll derivative is not suitable for PDT studies.

It is interesting to notice the occurrence of a well defined sigmoid profile that is typical of many solvent binary mixture systems. In fact, Roses and co-workers ${ }^{20-22}$ and Takayanagi and co-workers ${ }^{23}$ have studied this behavior, which is probably related to the association of several factors, such as auto-protolysis and solute-solvent/solventsolvent interactions.

Figure 8 and its inset show that, above $40 \%$ of water, the RLS intensity for magnesium and zinc chlorophylls decreases abruptly, reaching a minimum light scattering from approximately $60 \%$ of water in ethanol/water mixture. 


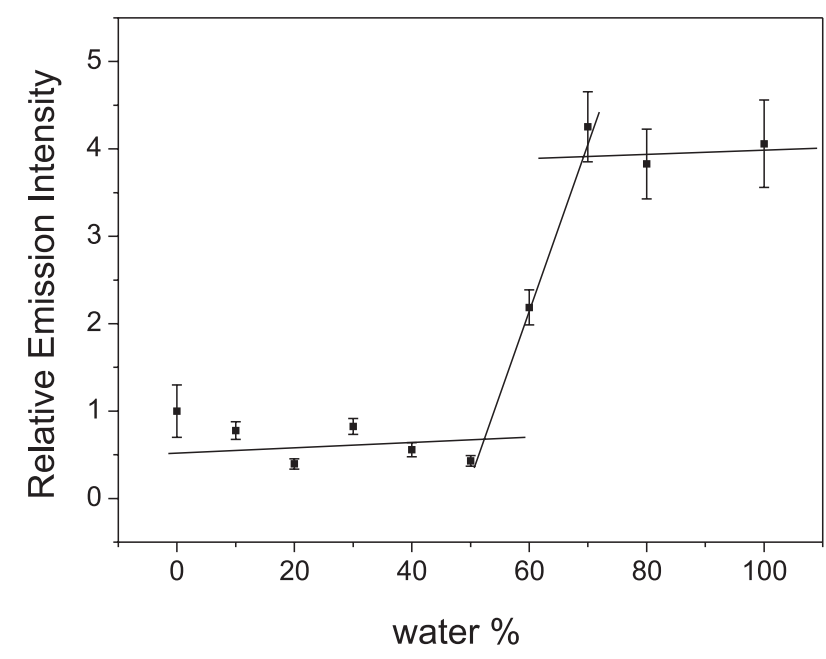

Figure 7. Variation of the relative emission intensity for copper chlorophyll as function of the solvent composition, at $298.15 \mathrm{~K}$.

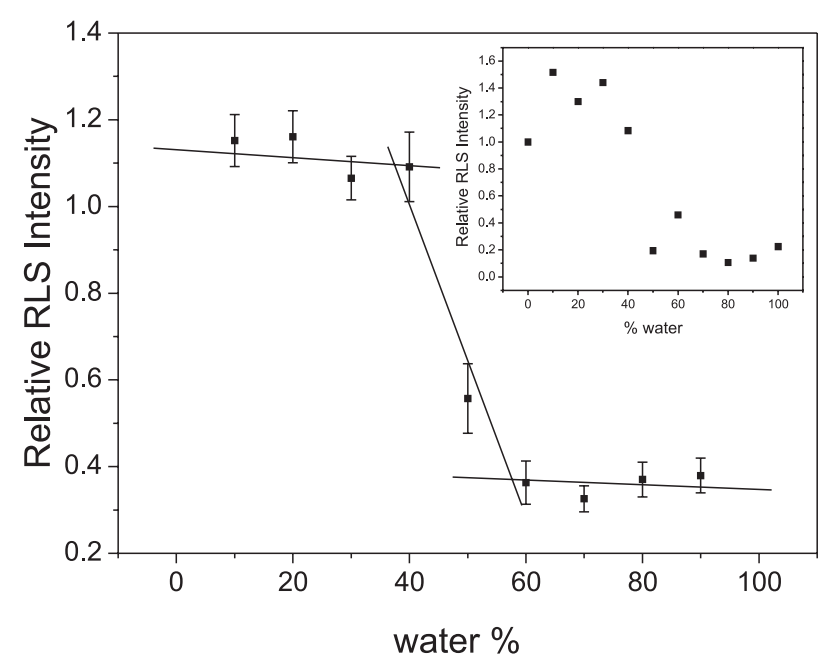

Figure 8. Variation of RLS relative intensity for magnesium chlorophyll as function of the solvent composition at $298.15 \mathrm{~K}$. Inset: Changes in the relative intensity of RLS for zinc chlorophyll, as function of the solvent composition, at $298.15 \mathrm{~K}$.

This suggests that above this water proportion the aggregation process should be profoundly maximized. Thus, this is the optimal condition of a possible application of magnesium and zinc chlorophylls as phototherapeutic agents in PDT. It is known that the aggregation of photosensitizer molecules tends to reduce or suppress their photodynamic activity. This effect is attributed to the fact that the formation of aggregates tend to deactivate the excited states preferentially by non-radiative processes. ${ }^{24,25}$ For copper chlorophyll a less drastic and well defined inflexion is observed (not shown).

The present results denote that a minimum presence of $60 \%$ of water in the water/ethanol mixture represents an optimum optical condition for applications of $\mathrm{Zn}^{2+}$ and $\mathrm{Mg}^{2+}$ chlorophylls in PDT studies. Ethanol and water are probably disposed in an adequate form, generating some kind of double layer between the metallic complexes and thus inhibiting the formation of dimers ${ }^{26}$ and consequently macrocycle aggregation. Based on the important role due to the water to minimize the aggregation phenomena, water molecules should be preferentially in contact with the metallic centre, as consequence of the high charge density of these ions as well as the higher dielectric constant of water when compared with ethanol.

\section{Conclusions}

The present results denote that magnesium and zinc chlorophyll have a higher potential to be employed as photosensitizers in PDT as function of their highest absorption and emission intensities. Furthermore, independently of the chlorophyll evaluated in the spectroscopic measurements, the presence of at least $60 \%$ of water in the solvent mixture generates a higher intensity of absorption and emission. Probably, this fact is a direct consequence of the lower aggregation process, in agreement with the RLS data. These optimal conditions must be considered in a process of preparation of new photosensitizers to be applied in PDT. New studies are in course in our group to improve our understanding focused on the molecular mechanisms of the solvent influence on the photophysical properties of macrocyclic compounds.

\section{Acknowledgments}

Thanks are due to FAPESP (06/56701-3, 02/00272-6 and 08/50588-6), Fundação Araucária, FAPEMIG (EDT 515/05 and 102/06, CEX APQ-0571-5.02/08 and CEX 652/05), CNPq (300391/2005-6, 473920/20077, 470869/2006-2 and 479655/2008-1) and Nanobrax (www.nanobrax.com). A. Lima (IC), Antonio E. H. Machado (PQ-1C) and N. Hioka (PQ-2) are grateful to $\mathrm{CNPq}$ for their respective grants.

\section{References}

1. Vokacová, Z.; Burda, J. V.; J. Phys. Chem. A 2007, 111, 5864.

2. Dolphin, D.; The Porphyrins; Physical Chemistry, Part C, vol. V; Academic Press: New York, 1978.

3. Lima, A.; Moreira, L. M.; Gracetto, A.; Batistella, V.; Gerola, A. P.; Hioka, N.; Severino, D.; Machado, A. E. H.; Rodrigues, M. R.; de Oliveira, H. P. M., unpublished work.

4. Dujardin, E.; Laszio, P.; Sacks, D.; J. Chem. Educ. 1975, 52, 742.

5. Tomo, T.; Okubo, T.; Akimoto, S.; Yokono, M.; Miyashita, H.; Tsuchiya, T.; Noguchi, T.; Mimuro, M.; Proc. Natl. Acad. Sci. U. S. A. 2007, 104, 7283. 
6. Novoderezhkin, V. I.; Dekker, J. P.; van Grondelle, R.; Biophys. J. 2007, 93, 1293.

7. Groot, M. L.; Pawlowicz, N. P.; van Wilderen, L. J. G. W.; Breton, J.; van Stokkum, I. H. M.; van Grondelle, R.; Proc. Natl. Acad. Sci. U. S. A. 2005, 13, 1387.

8. Liu, S.; Dong, F.; Yang, C.; Tang, C.; Kuang, T.; J. Integr. Plant Biol. 2006, 48, 1330.

9. Losev, A. P.; Nichiporovich, I. N.; Zhuravkin, I. N.; Zhavrid, E. A.; Proc. SPIE 1996, 2675, 243.

10. Moser, J. G. In Photodynamic Tumor Therapy, $2^{\text {nd }}$ and $3^{\text {rd }}$ Generation Photosensitizers; Moser, J. G., ed.; Harwood: India, 1998.

11. Ferreira, S. D. R. M.; Tedesco, A. C.; Souza, G.; Zângaro, R. A.; Silva, N. S.; Pacheco, M. T. T.; Pacheco-Soares, C.; Laser Med. Sci. 2004, 18, 207.

12. Nakagawa, H.; Matsumiya, T.; Sakaki, H.; Imaizumi, T.; Kubota, K.; Kusumi, A.; Kobayashi, W.; Kimura, H.; Oral Oncol. 2007, 43, 544.

13. Sibrian-Vazquez, M.; Jensen, M. J.; Vicente, G. H. J.; Photochem. Photobiol. B 2007, 86, 9.

14. Silva, N. S.; Ribeiro, C. M.; Machado, A. H. A.; Pacheco-Soares, C.; Vet. Parasitol. 2007, 146, 175.

15. Machado, A. E. H.; Quim. Nova 2002, 23, 237.

16. Simplicio, F. I.; Maionchi, F.; Hioka, N.; Quim. Nova 2000, 25, 801.
17. Björn, L. O. In Photobiology: The Science of Life and Light, $2^{\text {nd }}$ ed.; Björn, L. O., ed.; Springer: New York, 2008.

18. Socaciu, C. In Food Colorants: Chemical and Functional Properties; Socaciu, C., ed.; CRC Press: New York, 2007.

19. Henderson, B. W.; Dougherty, T. J. In Photodynamic Therapy: Basic Principles and Clinical Applications; Henderson, B. W.; Dougherty, T. J., eds.; CRC Press: New York, 1992.

20. Fonrodona, G.; Ràfols, C.; Bosch, E.; Rosés, M.; Anal. Chim. Acta 1996, 335, 291.

21. Bosch, E.; Ràfols, C.; Rosés, M.; Anal. Chim. Acta 1995, 302, 109.

22. Muinasmaa, U.; Ràfols, C.; Bosch, E.; Rosés, M.; Anal. Chim. Acta 1997, 340, 133.

23. Kaneko, H.; Hanami, K.; Yoshimura, N.; Takayanagi, M.; Chem. Phys. Lett. 2007, 448, 31.

24. Darwent, J. R.; Douglas, P.; Harriman, A.; Porter, G.; Richoux, M. C.; Coord. Chem. Rev. 1982, 44, 83.

25. Tanielian, C.; Heinrich, G.; Photochem. Photobiol. 1995, 61, 131.

26. Nsangou, M.; Ben Fredjb, A.; Jaidaneb, N.; Kwato Njocka, M. G.; Ben Lakhdarb, Z.; THEOCHEM 2005, 726, 245.

Received: October 29, 2008

Web Release Date: September 11, 2009

FAPESP helped in meeting the publication costs of this article. 